\title{
Adsorption of depocolin and inhibition of copper dissolution in aqueous solutions
}

\author{
O.Yu. Grafov,* L.P. Kazansky, S.V. Dubinskaya and Yu.I. Kuznetsov \\ A.N. Frumkin Institute of Physical Chemistry and Electrochemistry, Russian Academy \\ of Sciences, Leninsky pr. 31, 119071 Moscow, Russian Federation \\ *E-mail: grafov.oleg88@gmail.com
}

\begin{abstract}
The work is devoted to a study of an interesting representative macrocycle compound 3,7,12,17-tetramethyl-8,13-divinyl-2,18-porphinedipropionic acid disodium salt (depocolin) containing two peripheral carboxylic groups. The inhibiting action and adsorption on copper in neutral borate buffered solutions depending on depocolin concentration were studied. Using electrochemical curves, the influence of the inhibitor on the behavior of copper in solution was determined. It was shown that at depocolin concentrations above $0.25 \mathrm{mmol} / \mathrm{l}$, stabilization of the passive state of copper in neutral chloride solutions ( $\mathrm{pH} 7.4$ ) was observed, which was also confirmed by corrosion tests. The method of X-ray photoelectron spectroscopy was used to determine the composition and thickness of surface films. It was deduced from XPS analysis that depocolin is bonded to copper cations through two donor atoms of oxygen of the carboxyl groups. The nitrogen atoms do not participate in the formation of coordination bonds with copper cations. The calculated thickness of the adsorbed depocolin layer is proved to be $1.2 \mathrm{~nm}$ corresponding to the fixation of the molecule plane at an angle of $55^{\circ}$ to the copper surface. Treatment of a sample in an ultrasonic bath did not remove the depocolin layer, which is an indication of the chemisorption character of bonding of the latter with copper. The inhibiting capability of depocolin was studied in a chamber with periodic moisture condensation and in a chamber with neutral salt fog. The samples modified with depocolin showed a higher corrosion resistance.
\end{abstract}

Key words: copper, depocolin, inhibitor, porphyrins, electrochemistry, XPS, corrosion.

Received: April 16, 2019. Published: July 18, 2019

doi: $\underline{10.17675 / 2305-6894-2019-8-3-6}$

\section{Introduction}

Recently a class of organic compounds such as porphyrins starts to attract a great interest. This is explained by their broad application in various fields of science and technology: from heterogeneous catalysis [1,2] to molecular electronic engineering [3], optoelectronics [4], various dyes [5-8] and gloss-forming additives [9, 10].

Porphyrins represent the cyclic aromatic polyamines containing a multiple loop conjugated system, derivatives of porphin (Figure 1a). 
Due to the molecular sizes, porphyrins and their metal complexes can efficiently interfere with access of an oxidizer to a metal. In most cases, the molecules of porphyrins are adsorbed parallel to the substrate plane as shown in [11-14], where adsorption of cobalt porphyrins on silver and gold surfaces was studied. This statement was also confirmed by theoretical calculations in $[15,16]$ and it was shown that the plane of porphyrin macrocycle is aligned the surface of $\mathrm{Cu}(110)$ and forms a chemisorption bond with the substrate due to electron transfer on vacant $\pi$ orbital of porphyrin. Thus, in [17] chemisorption of cobalt(II) porphyrin takes place due to the strong coupling of $\pi$-electrons in the aromatic structure of porphyrin and overlapping of d-orbitals of the cobalt(II) ion to the copper surface.
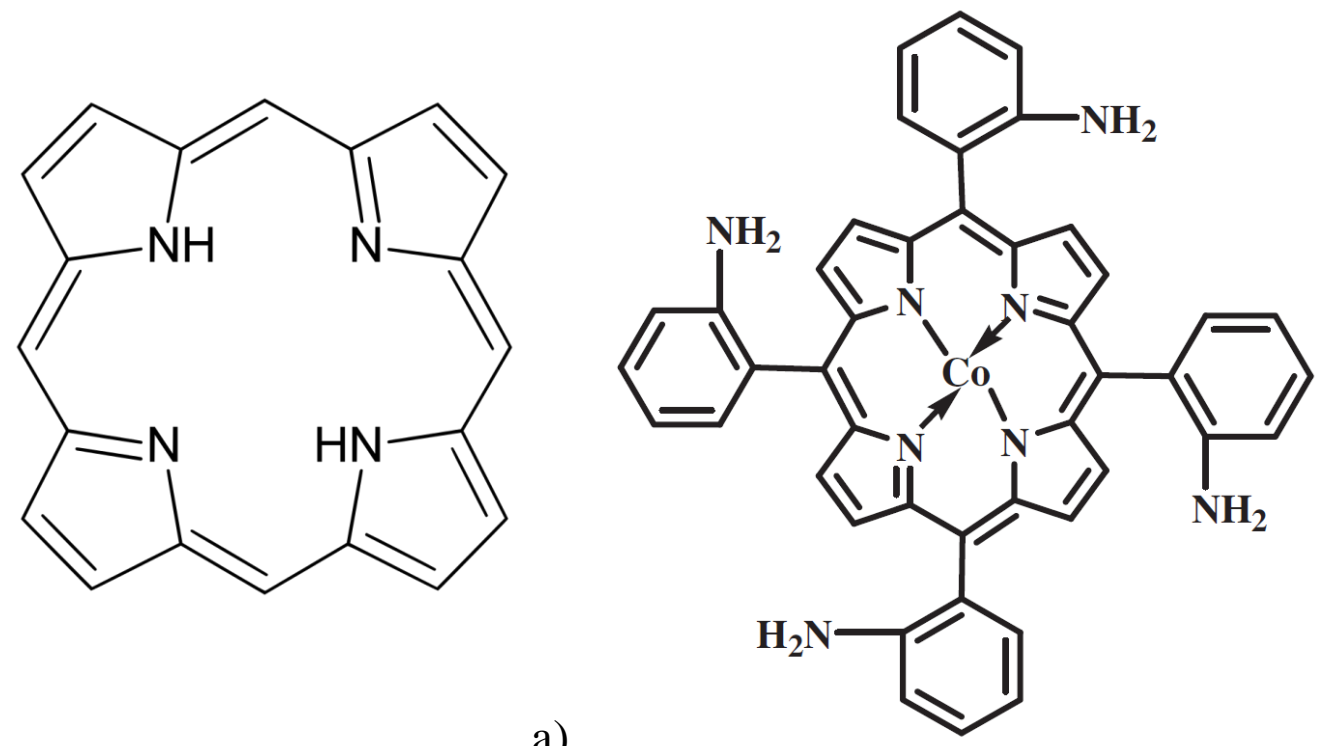

a)

b)

Figure 1. Molecular structures of porphin (a) and cobalt porphyrin (b).

Owing to the properties described above, metal-less porphyrins and their complexes found application as inhibitors preventing corrosion of metals [18-20]. For example, addition of $1 \mathrm{mmol} / 1$ of the cobalt complex (Figure 1b) gave a protection degree $Z=98 \%$ in $0.1 \mathrm{M}$ sodium sulfate solution [17], while addition of $0.3 \mathrm{mmol} / 1$ of the complex with $\mathrm{Fe}^{3+}$ provided $Z=97 \%$ in $1 \mathrm{M}$ hydrochloric acid.

In the present work, the adsorption of depocolin on the copper surface from neutral aqueous solutions and also its ability to inhibit copper dissolution were studied.

\section{Experimental}

Electrochemical and adsorption studies were conducted in a borate buffer solution with $\mathrm{pH} 7.40$ that was prepared from recrystallized borax and boric acid in double distilled water [21]. 
Anodic polarization curves on copper electrode (area $S=1.25 \mathrm{~cm}^{2}$ ) were recorded using an electrochemical cell with separated electrode spaces and an IPC-PRO potentiostat managed by a computer. The working electrode was preliminarily polished with sandpapers of different grains to a mirror finish and degreased with acetone. The electrode potentials $(E)$ were measured relative to a silver chloride electrode and recalculated to the normal hydrogen scale. A platinum plate served as the counter electrode. After removal of the oxide layer formed in air by cathodic polarization of an electrode at $E=-0.60 \mathrm{~V}$ $(15 \mathrm{~min})$, the potentiostat was disconnected until a free corrosion potential $E_{\mathrm{C}}$ was attained, and then depocolin and sodium chloride solution were introduced with stirring by means of a magnetic stirrer $(2 \mathrm{~min})$. After a new $E_{\mathrm{C}}$ value was established, the anodic and cathodic polarization curves were measured with a potential scan rate of $0.2 \mathrm{mV} / \mathrm{s}$. The pitting potential $\left(E_{\mathrm{p}}\right)$ was determined by a sharp growth of current on the polarization curve with subsequent visual identification of pitting on the electrode surface.

Samples for X-ray-photoelectron spectroscopy (XPS) studies were made as copper M0 plates of $10 \times 20 \mathrm{~mm}^{2}$ which were processed similarly to those for the electrochemical studies, ground with emery paper (1000), then (2500), polished with diamond paste (Ted Pella, Inc., $0.25 \mu \mathrm{m}$ ) to a mirror finish, degreased with ethanol, and washed in an ultrasonic bath. After that, the samples were placed in a solution of porphyrin with a concentration of $0.1 \mathrm{mmol} / 1$ and kept there for 1 to $180 \mathrm{~min}$. After exposure the surface of a sample was carefully washed with a stream of distilled water, washed ultrasonically and transferred into the preliminary pumping chamber of the spectrometer.

An OMICRON ESCA+ spectrometer was used to analyze the quantitative and qualitative composition of the surface layers. The pressure in the analyzer chamber did not exceed $8 \cdot 10^{-10}$ Mbar. An Al-anode was the source of radiation (radiation energy $1486.6 \mathrm{eV}$ and power of $252 \mathrm{~W}$ ). The pass energy of the analyzer was set at $20 \mathrm{eV}$. To account the charging of samples, the positions of XP peaks were standardized by the C1s peak of hydrocarbon contaminations from the atmosphere, whose binding energy was accepted to be $285.0 \mathrm{eV}$.

Deconvolution of the spectra into components was carried out after the subtraction of the background determined by Shirley's method [22,23]. The peak positions were determined with an accuracy of $\pm 0.1 \mathrm{eV}$. The atomic ratios of elements were calculated using the integral intensities under the peaks, taking into account the photo-ionization cross-sections $\sigma$ of the corresponding electronic shells [24]. By means of the MultiQuant [25] program, the thicknesses of the layers formed on the surface were calculated using the integral intensity of peaks and taking into account the average free path of electrons $\lambda$ determined by Cumpson and Seah's formula [26].

To study the quantitative and qualitative composition of the layers, which are formed on the surfaces of metal samples in the presence of depocolin, the C1s, N1s, O1s, CuLMM and $\mathrm{Cu} 2 \mathrm{p}_{3 / 2}$ ranges were analyzed. The ranges were processed by the Unifit (C) 2009 
program. The adsorption of porphin on the copper surface was proved by the complex spectra of carbon $\mathrm{C} 1 \mathrm{~s}$ and nitrogen $\mathrm{N} 1 \mathrm{~s}$ electrons.

Corrosion tests were carried out in a humid atmosphere with periodic condensation of moisture on copper M0 samples. Test samples were cut out from copper sheets M0, ground with emery paper (1000), then (2500), polished with diamond paste (Ted Pella, Inc., $0.25 \mu \mathrm{m})$ to a mirror finish, then degreased with ethanol and washed in an ultrasonic bath. The samples were kept in borate buffer in order to stabilize the oxide film, then immersed in a solution of inhibitors with $C_{\text {in }}=1.0 \mathrm{mmol} / 1$ for $5 \mathrm{~min}$ at room temperature. After passivation, the samples were transferred to a sealed cell at the bottom of which water with $t=50 \pm 1^{\circ} \mathrm{C}$ was poured. Periodic condensation of moisture was carried out by replacing water in the cell once a day. The efficiency of passivation was assessed by the time until the appearance of the first corrosion damage $\left(\tau_{\text {corr }}\right)$.

Corrosion tests of copper were carried out in neutral salt fog according to GOST 28234-89 in a Umwelttechnik Weiss SC-450 chamber (FRG). Test samples were cut out from copper sheets M0, ground with emery paper (1000), then (2500), polished with diamond paste (Ted Pella, Inc., $0.25 \mu \mathrm{m}$ ) to a mirror finish, then degreased with ethanol and washed in an ultrasonic bath. Then the samples were placed for $5 \mathrm{~min}$ in $2 \mathrm{mmol} / 1$ solution of the studied inhibitor at room temperature, dried in air for 1 hour and suspended in the salt fog chamber. The tests consisted of periodic dispersion $(15 \mathrm{~min}) /$ condensation (45 min) of salt brine in the chamber at an interval of 1 hour. After the exposure, a quantitative analysis of the state of sample surfaces was carried out: the surface fraction that underwent corrosion damage, the nature of damage, and the impact of an inhibitor on the course of corrosion processes were studied.

\section{Results and discussion}

In this work we used 3,7,12,17-tetramethyl-8,13-divinyl-2,18-porphinedipropionic acid disodium salt (depocolin) whose formula is presented in Figure 2.

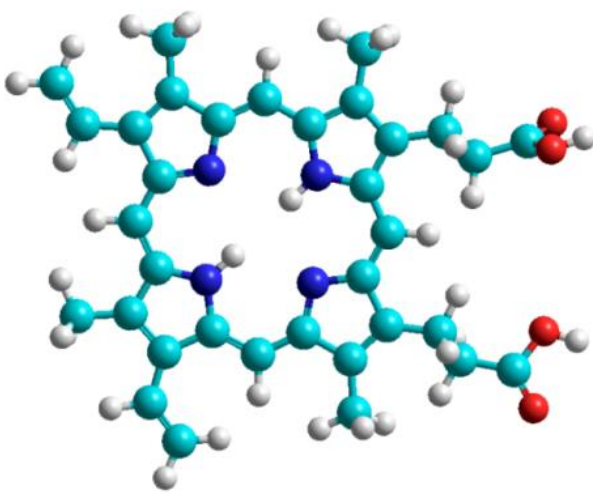

a)

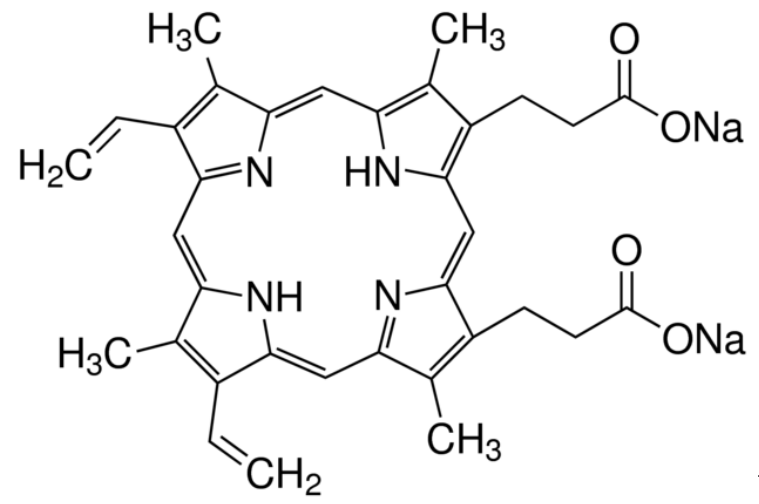

b)

Figure 2. Structural formula of depocolin (a) and its sodium salt (b). 


\section{Potentiodynamic studies}

In studies on the influence of depocolin on the $E_{\mathrm{C}}$ of copper, the primary oxide on its surface was first removed by cathodic polarization in borate buffer, and then the potentiostat was disconnected for 15 min until a free $E_{\mathrm{C}}$ was established. A depocolin concentrate was added to the solution to obtain $C_{\text {inh }}$ ranging from 0.1 to $2 \mathrm{mmol} / \mathrm{l}$. With an increase in the concentration of the additive, the $E_{\mathrm{C}}$ shifted to more positive values (Table 1) relative to the sample without an additive.

Table 1. Variation of $E_{\mathrm{C}}$ depending on the depocolin concentration.

\begin{tabular}{cccccc}
\hline $\boldsymbol{C}_{\mathrm{inh}}, \mathbf{m m o l} / \mathbf{l}$ & $\mathbf{0}$ & $\mathbf{0 . 1}$ & $\mathbf{0 . 2 5}$ & $\mathbf{1}$ & $\mathbf{2}$ \\
\hline $\boldsymbol{E}_{\mathbf{C}}, \mathbf{V}$ & 0.098 & 0.120 & 0.125 & 0.130 & 0.150 \\
\hline
\end{tabular}

In Figure 3 one can that even at a low concentration of $0.1 \mathrm{mmol} / \mathrm{l}$, there is a considerable decrease in the passivation current density. However, $E_{\mathrm{pt}}$ at this concentration is shifted to more negative values.

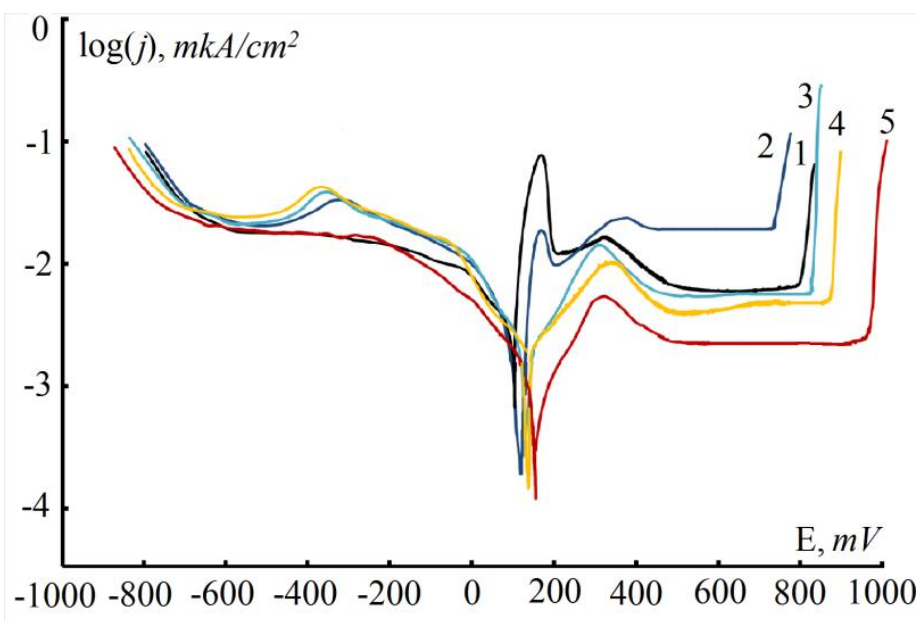

Figure 3. Tafel plots for copper electrode in borate buffer (pH 7.4) containing $0.01 \mathrm{~mol} / \mathrm{l} \mathrm{NaCl}$ (1) and depocolin (mmol/l): $2-0.1 ; 3-0.25 ; 4-1 ; 5-2$.

Presumably, it may be explained by the fact that layer of depocolin that is formed is not sufficiently dense to protect the surface against pitting caused by chloride, but already promotes the passivation of the electrode. Depocolin is also believed to prevent the formation of $\mathrm{Cu}_{2} \mathrm{O}$. On further increase in inhibitor concentration, a denser layer is formed, so, for example, at a concentration of $0.25 \mathrm{mmol} / 1$ the passivation current density decreases 90-fold relative to that in a solution without depocolin. This trend is also observed with a further increase in the inhibitor concentration. The pitting potential is also 
shifted in the positive direction with an increase in concentration, and the protective effect reaches $\Delta E=E_{\mathrm{pt}}-E_{\mathrm{pt}}^{\mathrm{bg}}=0.160 \mathrm{~V}$ at a depocolin concentration of $2 \mathrm{mmol} / \mathrm{l}$ (Table 2).

Table 2. Change in protective effect $\Delta E$ depending on the depocolin concentration.

\begin{tabular}{ccccc}
\hline $\boldsymbol{C}_{\text {inh }}, \mathbf{m m o l} / \mathbf{l}$ & $\mathbf{0 . 1}$ & $\mathbf{0 . 2 5}$ & $\mathbf{1}$ & $\mathbf{2}$ \\
\hline$\Delta \boldsymbol{E}, \mathrm{V}$ & -0.058 & 0.030 & 0.100 & 0.160 \\
\hline
\end{tabular}

\section{$X$-Ray photoelectron studies}

The structure of depocolin, like all the metal-less porphyrins, contains two types of nitrogen: pyrrole and pyridine that will be correlated with the recorded XPS-data of a powder of the studied substance (Figure 4a). In the XP spectrum of N1s electrons of depocolin powder, two peaks are observed, one with a higher binding energy comes from the protonated nitrogen $\left(E_{\mathrm{b}}=400.1 \mathrm{eV}\right)$, and the other one with a smaller energy is caused by non-protonated nitrogen $\left(E_{\mathrm{b}}=398.2 \mathrm{eV}\right)$.
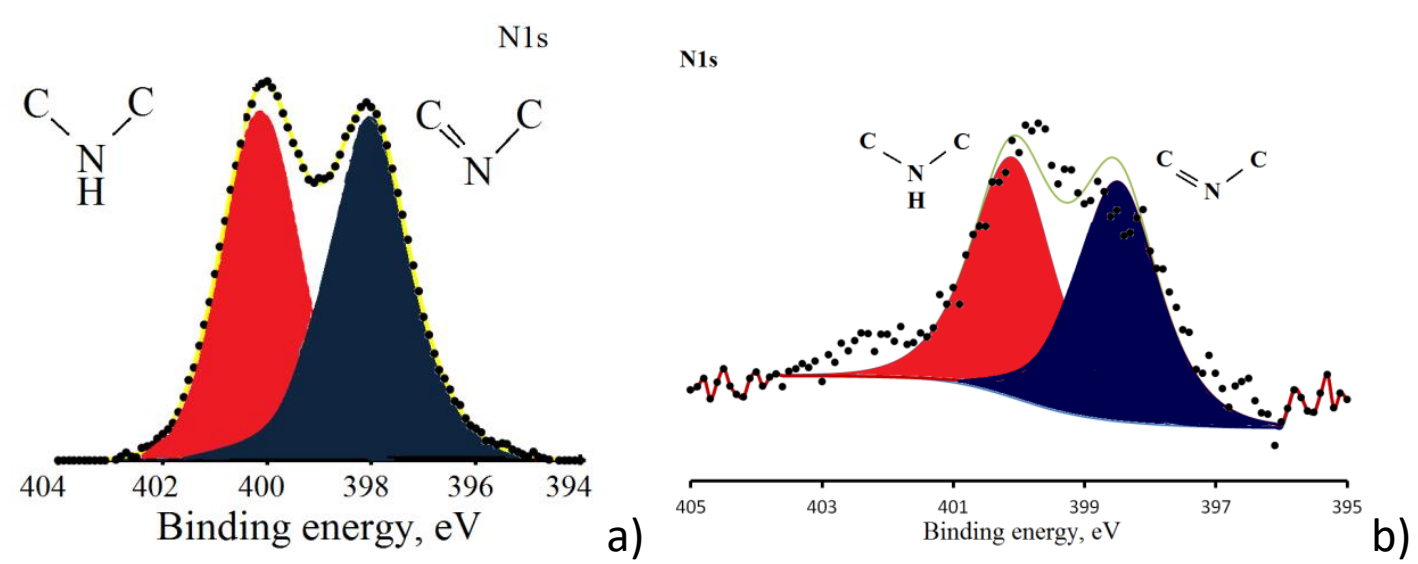

Figure 4. N1s spectrum of depocolin powder (a) and (b) depocolin adsorbed on the copper surface.

A similar spectrum is also observed for depocolin adsorbed on copper surface from solution (Figure $4 \mathrm{~b}$ ). The positions of the peaks do not change.

In the XP spectrum of $\mathrm{Cu} 2 \mathrm{p}_{3 / 2}$ electrons, a single peak, whose position may correspond both to metal copper and cuprous oxide [27], is observed (Figure 5a). The existence of $\mathrm{Cu}_{2} \mathrm{O}$ and metal copper is confirmed by the Auger spectrum of CuLMM electrons (Figure 5b), which can be decomposed into two components whose maxima may be assigned to $570.4 \mathrm{eV}\left(\mathrm{Cu}_{2} \mathrm{O}\right)$ and to $568.4 \mathrm{eV}\left(\mathrm{Cu}^{0}\right)$. 

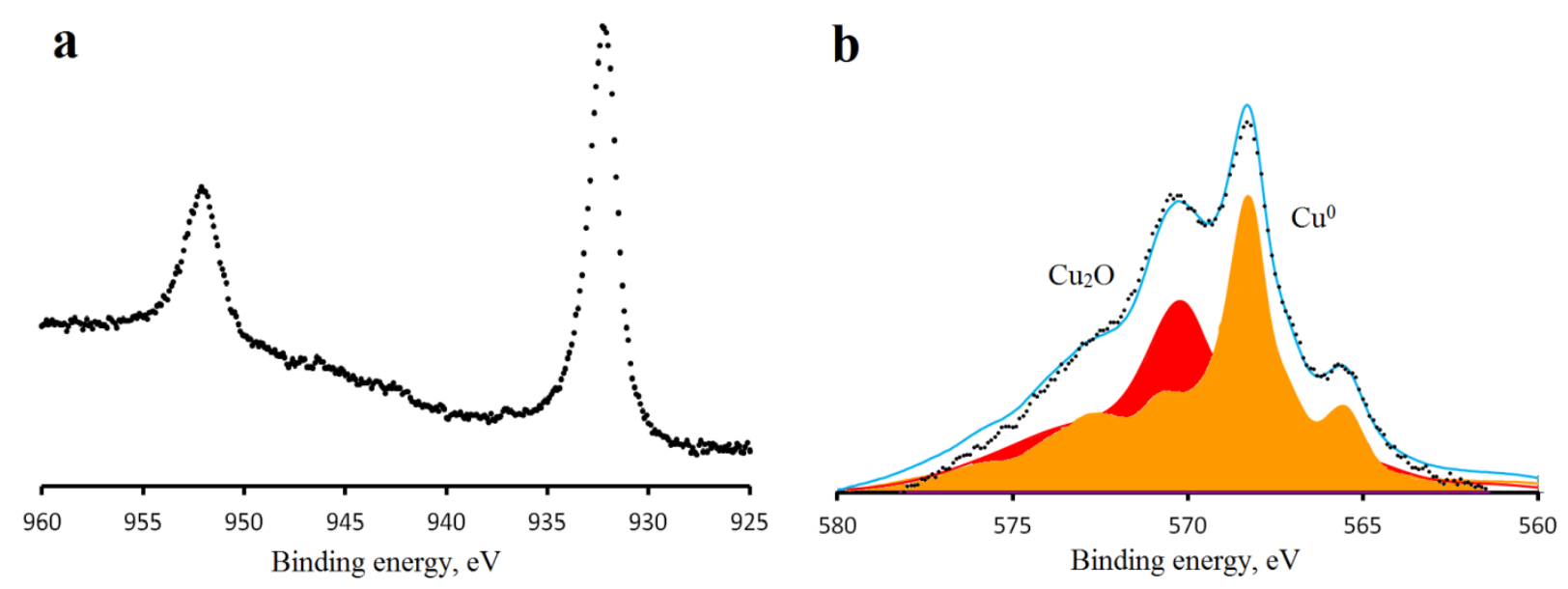

Figure 5. XP spectra: Cu2p (a), CuLMM of copper sample after exposure in depocolin solution (b).



Figure 6. XP spectra of C1s electrons of depocolin adsorbed on copper surface.

Depocolin adsorption on the copper surface is confirmed by the presence of peaks in the carbon spectrum of C1s electrons: $\mathrm{CN}(286.4 \mathrm{eV})$ and $\mathrm{COO}^{*} \mathrm{Me}(288.6 \mathrm{eV})$ (Figure 6).

From the calculated areas of the integrated intensities under the peaks by means of the XPS MultiQuant program, the thicknesses of the following layers were calculated: carbon contamination $(1.4 \mathrm{~nm})$, hydroxylated layer $(0.7 \mathrm{~nm})$, depocolin layer $(1.2 \mathrm{~nm})$ and $\mathrm{Cu}_{2} \mathrm{O}$ layer $(2.1 \mathrm{~nm})$.

As careful washing of the copper surface and placing a sample into a vacuum practically does not affect the estimation of the quantity of adsorbed depocolin, it is 
possible to assume that the macromolecule is strongly anchored to the copper surface and that this bonding has a chemisorption character.

It should be noted that in the XP spectrum of N1s electrons two peaks of identical intensity caused by two types of atoms of nitrogen are observed, whose positions did not change upon adsorption. It may indicate that during adsorption of the anion, the porphyrin ring does not participate in bonding with the copper cation. The most probable anchoring of the depocolin molecule to the surface of copper is through carboxyl groups. We can assume that the depocolin molecules are orientated at an angle of $55^{\circ}$ to the copper surface.

\section{Corrosion studies}

In the corrosion studies with periodic condensation of moisture, the samples modified with depocolin showed higher corrosion resistance than the samples without immersion in the depocolin solution. The first traces of corrosive lesions on the samples treated in depocolin solution started to appear after 22 days (Figure 7b), while the first traces of corrosive lesions of non-treated samples were found after the first day (Figure 7a).

a

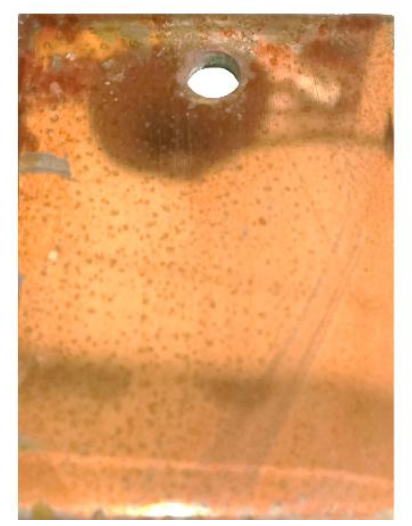

b

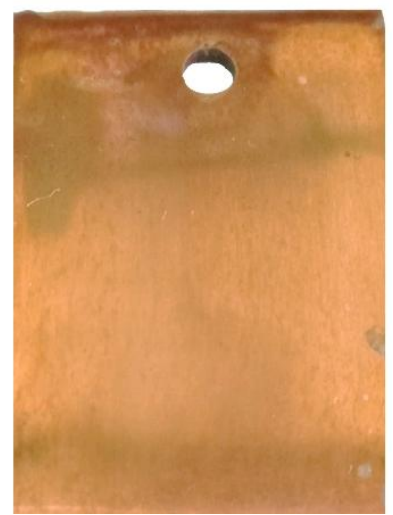

Figure 7. Copper samples after corrosion studies with periodic condensation of moisture:

(a) - without treatment after 1 day, (b) - with depocolin treatment after 22 days.

The inhibiting capability of depocolin for copper was also confirmed by direct corrosion tests of copper plates. The plates treated and not treated by the porphyrin were placed in the neutral salt fog chamber for 1 and $4 \mathrm{~h}$. Immediately $1 \mathrm{~h}$ later, the first corrosion damages were observed on plates without the treatment, however, the samples treated by the inhibitor were free of corrosion damage. After 2 hours, the zone of corrosion lesions increased on the samples without the treatment (Figure 8a), whereas no lesions were detected on the samples treated with depocolin (Figure 8b). $4 \mathrm{~h}$ later, the area of corrosion damages with apparent deep pitting considerably increased on samples without 
treatment (Figure 9a), while on samples treated with depocolin, only traces of general corrosion and insignificant pitting were noticeable (Figure 9b).
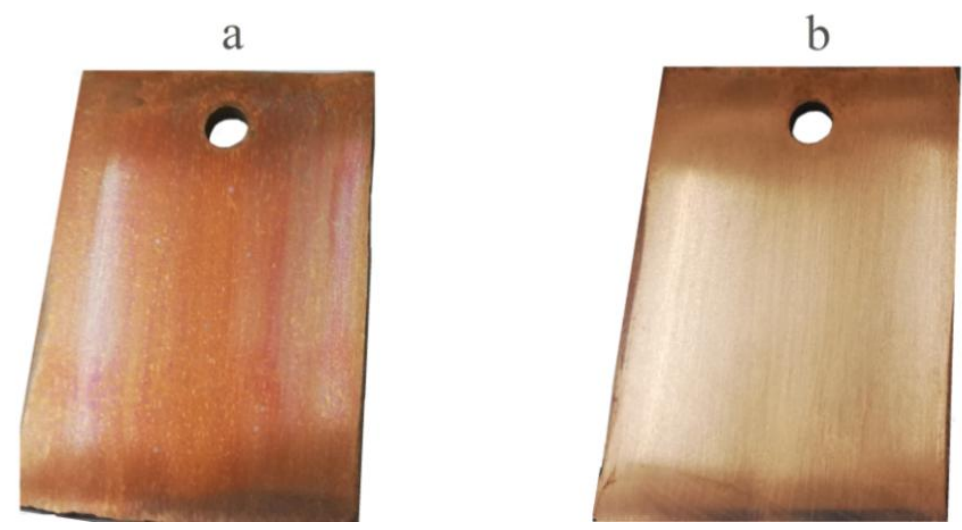

Figure 8. Copper samples after 2 hours in the neutral salt fog chamber: (a) - without treatment, (b) - with treatment by depocolin.
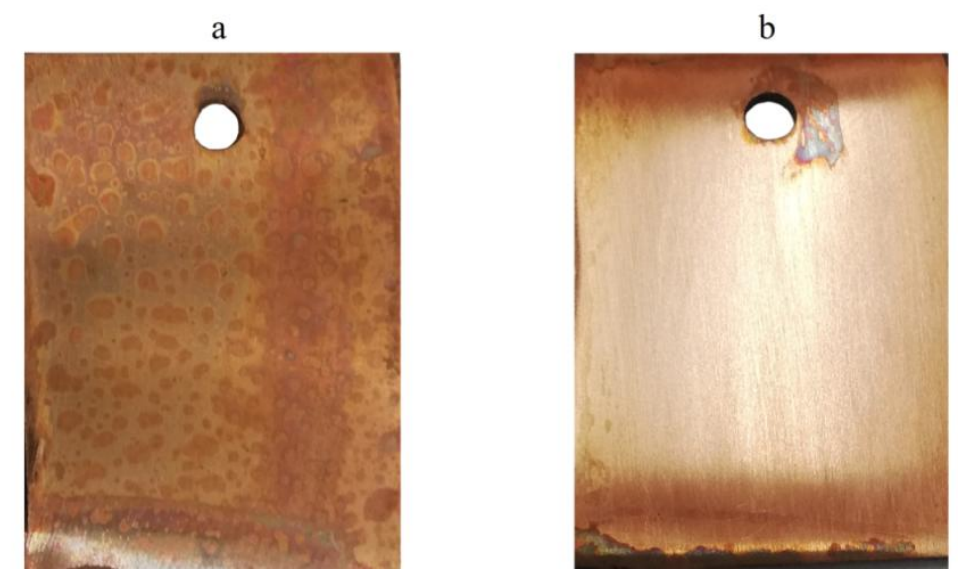

Figure 9. Copper samples after 4 hours in the neutral salt fog chamber: (a) - without treatment, (b) - with treatment by depocolin.

\section{Conclusions}

1. At depocolin concentration above $0.25 \mathrm{mmol} / \mathrm{l}$, stabilization of the passive state of copper in neutral chloride solutions $(\mathrm{pH} 7.4)$ is observed that is also confirmed by corrosion tests.

2. XPS studies show that depocolin is bound with copper cations through two donor atoms of oxygen of the carboxyl groups. Atoms of nitrogen don't participate in the formation of coordination bonds with copper cations.

3. The thickness of the adsorbed depocolin layer is $1.15 \mathrm{~nm}$, which makes it possible to assume that molecules are fixed at an angle 55 degrees to the surface. The high anchoring strength with the surface indicates that chemisorption occurs. 


\section{Acknowledgments}

This work was supported by the State scientific program No. 14P "Physical chemistry of adsorption phenomena and actinide nanoparticles" for 2019 and partly by State Order "Development of the fundamental scientific basis for the protective action of metal corrosion inhibitors in gas and condensed media, nanocomposites, paintwork and conversion coatings". \#AAAA-A 18-119-121090043-0

\section{References}

1. S.M. Barlow and R. Raval, Surf. Sci. Rep., 2003, 50, 201.

2. M. Castonguay, J.R. Roy, A. Rochefort and P.H. McBreen, J. Am. Chem. Soc., 2000, 122 , no. $3,518$.

3. C. Joachim, J.K. Glimzewski and A. Aviram, Nature, 2000, 408, 541-548.

4. S.R. Forrest, Chem. Rev., 1997, 97 no. 6, 1793.

5. K.A. Askarov, B.D. Berezin, E.V. Bystritskaya et al, Ed. N.S. Enikolopyan, Porfiriny: Spektroskopiya, Elektokhimiya, Primenenie (Porphyrins: Spectroscopy, Electrochemistry, Application), Nauka, Moscow, 1987, 384 (in Russian).

6. K.M. Smith, Porphyrins and Metalloporphyrins, Amsterdam, Oxford, New York, Elsevier, 1975, 900.

7. B.D. Berezin, Koordinatsionnye soedineniya porfirinov i ftalotsianinov (Coordination compounds of porphyrins and phthalocyanins), Nauka, Moscow, 1979, 280 (in Russian).

8. M.P. Tarasevich, K.A. Radushkina and V.A. Bogdanovskaya, Electrokhimiya porphirinov (Electrochemistry of porphyrins), Nauka, 1991, 310 (in Russian).

9. O.A. Golubchikov, A.V. Larionov, A.V. Balmasov and V.E. Mayzlish, Izv. Vuzov. Khim. i Khim. Tekhnol., 2014, 57, no. 12, 60 (in Russian).

10. O.A. Golubchikov, A.V. Larionov, A.V. Balmasov and A.S. Semeykin, Macroheterocycles, 2014, 7, no. 3, 225.

11. Y. Bai, F. Buchner, I. Kellner, M. Schmid, F. Vollnhals, H.-P. Steinrück, H. Marbach and J.M. Gottfried, New J. Phys., 2009, 11, 125004.

12. J.M Gottfried and H. Marbach, Z. Phys. Chem., 2009, 223, 53.

13. W. Auwärter, A. Schiffrin, A. Weber-Bargioni, Y. Pennec, A. Riemann and J.V. Barth, Int. J. Nanotechnol., 2008, 5, 1171.

14. S. Yoshimoto and K. Itaya, J. Porphyrins Phthalocyanines, 2007, 11, 313.

15. M.S. Dyer, A. Robin, S. Haq, R. Raval, M. Persson and J. Klime, ACS Nano, 2011, 5, no. 3, 1831.

16. M. Spah, D.C. Spah, B. Deshwal, S. Lee, Y.-K. Chae and J.W. Park, Corros. Sci., 2009, 51, 1293.

17. K.S. Lokesh, M. De Keersmaecker, A. Elia, D. Depla, P. Dubruel, P. Vandenabeele, S. Van Vlierberghe and A. Adriaens, Corros. Sci., 2012, 62, 73. 
18. H. Junying, H. Daobing, G. Zhang, G.-L. Song and X. Guo, Electrochem. Solid-State Lett., 2012, 15, no. 6, 13.

19. Y. Feng, Sh. Chen, W. Guo, Y. Zhang and G. Liu, J. Electroanal. Chem., 2007, 602, 115.

20. Yu.I. Kuznetsov, M.O. Agafonkina, N.P. Andreeva and L.P. Kazansky, Corros. Sci., 2015, 100, 535.

21. Yu.V. Karyakin and I.I. Angelov, Chistye khimicheskie reaktivy (Pure chemical reagents), Moscow, Goskhimizdat, 1955, pp. 242, 365 (in Russian).

22. D.A. Shirley, Phys. Rev. B, 1972, 5, 4709.

23. M.A. Sherwood, Practical Surface Analysis by Auger and X-ray Photoelectron Spectroscopy (Appendix 3), Eds.: D. Briggs and M.P. Seah, Wiley, Chichester, 1983.

24. H. Scofield, J. Electron Spectrosc. Relat. Phenom., 1976, 8, 129.

25. M. Mohai, Surf. Interface Anal., 2004, 36, 828.

26. P.J. Cumpson and M.P. Seah, Surf. Interface Anal., 1997, 25, 430.

27. M.O. Agafonkina, Yu.I. Kuznetsov, N.P. Andreeva, Yu.E. Pronin and L.P. Kazansky, Korroz.: Mater., Zashch. (Corrosion: Materials, Protection), 2011, no. 7, 26 (in Russian). 